\title{
Rancang Bangun Pintu Air Otomatis Menggunakan Water Level Float Switch Berbasis Mikrokontroler
}

\author{
Heki Apriyanto \\ Politeknik Palcomtech Palembang \\ Jl. Basuki Rahmat No. 05 Palembang \\ heki_apriyant0@yahoo.com
}

\begin{abstract}
Abstrak - Penelitian ini bertujuan untuk membangun sistem pintu air otomatis membuka ataupun menutup pintu berdasarkan ketinggian air pada bendungan yang sebelumnya masih bersifat konvensional atau masih menggunakan tenaga manusia. Pintu air yang bersifat konvensional dinilai kurang efektif, mengingat curah hujan yang cukup tinggi disertai sulitnya memperkirakan ketinggian air yang selalu berubahubah, selain faktor tersebut ketinggian air pada suatu bendungan dipengaruhi juga oleh banjir kiriman didaerah lain. Metode penelitian yang digunakan dengan menggunakan pengumpulan data dan pengembangan perangkat yang terdiri dari perencanaan, analisis, perancangan dan implementasi, dimana dalam analisis menggunakan analisis SWOT untuk menilai layak atau tidaknya rancangan ini diterapkan. Hasil yang diharapkan adalah terwujudnya pintu air otomatis untuk meringankan manusia dalam menjalankan tugas serta membuat sistem yang berjalan dengan lebih efisien. Rancang bangun pintu air otomatis ini menggunakan mikrokontroler arduino uno dan nano sebagai alat pemroses, serta dilengkapi dengan sensor ultrasonik, water level float switch sensor, LCD display, motor servo. Water level float switch sensor yang berfungsi untuk memutar motor servo untuk mengangkat atau menurunkan pintu air sesuai batas ketinggian air. Hasil yang diharapkan adalah terciptanya sistem pintu air otomatis pada suatu bendungan dan dapat mengurangi kelalaian manusia dalam bertugas mengingat sulitnya memperkirakan ketinggian air yang selalu berubah-ubah dalam waktu tertentu.
\end{abstract}

Kata Kunci- Pintu Air, Bendungan, Otomatis, Water Level Float Switch Sensor, Motor Servo.

\section{Pendahuluan}

Indonesia merupakan sebuah negara dengan jumlah kepulaun terbanyak yang ada di dunia. Sebagai negara yang memiliki curah hujan tinggi, Indonesia menjadi sangat rentan sekali dengan bencana banjir. Fenomena banjir memang tidak dapat dihindari, namun untuk mengurangi dampak dari banjir dapat ditanggulangi dengan membuat bendungan atau waduk yang dilengkapi pintu air.

Bendungan adalah bangunan melintang sungai yang berfungsi untuk meninggikan muka air sungai, selain itu pemanfaatan bendungan untuk keperluan sektor-sektor yang menyangkut terhadap kebutuhan air seperti pembangkit tenaga listrik ataupun sistem irigasi sawah ataupun perkebunan.
Bendungan juga dilengkapi dengan pintu air yang dapat dioperasikan buka dan tutup secara bertahap ataupun secara terus-menerus guna kepentingan sesuai kebutuhan. Menurut Entatarina Simanjuntak (2010), pintu air adalah pintu/bangunan yang berfungsi untuk mengatur debit volume atau ketinggian air dan dapat dipasang pada waduk atau bendungan air atau diujung saluran yang berhubungan dengan badan air.

Pada era serba teknologi seperti ini, alangkah baiknya juga jika dimanfaatkan dalam pengendalian otomatis pintu air yang ada pada bendungan karena perubahan volume air yang selalu berubah-ubah dalam periode waktu yang tidak pasti. Sistem otomatis ini, diharapkan dapat lebih efektif dan efisien dalam mengurangi faktor kelalaian yang disebabkan manusia dapat dihindari seperti sering lalainya penjaga bendungan pintu air dalam mengendalikan pintu air yang menyebabkan ketidakstabilan volume air.

Berdasarkan latar belakang tersebut, maka dirancanglah sebuah alat yang mampu mendeteksi volume ketinggian air, dan alat tersebut juga dapat mengendalikan pintu air secara otomatis.

Masalah yang terjadi dapat diidentifikasi antara lain adalah lalainya petugas dalam mengontrol sistem buka tutup pintu air pada bendungan, kurang efisiennya sistem karena masih secara manual, dan jangkauan petugas dengan lokasi pintu air memerlukan waktu. Adapun tujuan dibuatnya rancangan pintu air otomatis ini adalah untuk mengurangi kelalaian petugas penjaga pintu air, agar lebih efisien dan efektif dalam pengendalian pintu air secara otomatis berdasarkan volume air yang sering berubah-ubah, dan efisiensi waktu.

\section{Metode Penelitian}

Dalam penyusunan tugas akhir ini untuk mendapatkan data yang akurat menggunakan metode penelitian pengumpulan data dan pengembangan perangkat yang terdiri dari perencanaan, analisis, perancangan, dan implementasi.

\section{A. Perencanaan}

Dalam perencanaan rancang bangun pintu air otomatis menggunakan water level float switch sensor berbasisi mikrokontroler arduino uno menggunakan analisis SWOT 
(Strength, Weakness, Opportunity, Threats) untuk menganalisa bahwa proyek yang sedang dirancang dapat diterapkan.

\section{B. Analisis} dari:

Analisis yang dilakukan dalam rancangan proyek ini terdiri

\section{1) Analisis Sistem Berjalan}

Analisis sistem berjalan, merupakan proses kerja sistem yang terjadi saat ini atau yang sedang berlangsung sebelum dikembangkannya proyek. Dalam tahap analisis sistem berjalan digambarkan dalam bentuk activity dan use case.

\section{2) Analisis Sistem Usulan}

Analisis sistem usulan, kebutuhan sistem yang digunakan untuk membangun pintu air otomatis ini menggunakan mikrokontroler arduino uno sebagai pemroses utama, mikrokontroler arduino nano sebagai pemroses pengukuran ketinggian air dan untuk menampilkan ke LCD, sensor ultrasonik sebagai pengukur ketinggian air, sensor air (water level float switch) yang berfungsi sebagai pendeteksi ketinggian, motor servo berfungsi sebagai pembuka atau penutup pintu air, dan LCD yang digunakan sebagai layar informasi ketinggian air. Dalam pembuatan program (editing) menggunakan software arduino IDE yang menggunakan pemrograman bahasa $\mathrm{C}$.

\section{3) Perancangan}

Perancangan dalam pembuatan pintu air otomatis dibagi menjadi empat tahapan perancangan, yaitu perancangan input yang menjelaskan alur kerja input sensor, perancangan proses yang mejelaskan alur kerja perfungsi antar komponen, perancangan output yang menampilkan proses kerja alat secara keseluruhan yang disusun dengan flowchart, serta perancangan model pintu air yang diusulkan.

\section{4) Implementasi}

Tahapan akhir dari suatu rancangan proyek adalah implementasi dari tahapan-tahapan sebelumnya. Implementasi menjelaskan semua proses instalasi dari mulai instalasi perangkat keras, instalasi perangkat lunak, tahap pemrograma, serta dilakukan tahapan pengujian yang berguna untuk mengetahui bahwa perangkat dapat berfungsi dengan benar, pada tahapan pengujian menggunakan metode blackbox guna menemukan kesalahan fungsi yang tidak benar atau hilang hingga kesalahan kerja dari suatu perangkat yang sedang dirancang.

\section{PembahasAn}

\section{A. Perencanaan}

Studi kelayakan pintu air otomatis menggunakan water level float switch sensor berbasis mikrokontroler arduino uno dilakukan menggunakan strategi analisis SWOT seperti yang terlihat pada tabel 1 .
Tabel 1. Analisis Swot Rancang Bangun Pintu Air Otomatis

\begin{tabular}{|c|l|}
\hline \multirow{3}{*}{ Strength } & $\begin{array}{l}\text { 1. Pintu dapat membuka dan } \\
\text { menutup secara otomatis }\end{array}$ \\
& $\begin{array}{l}\text { 2. Sistem dilengkapi dengan sensor } \\
\text { 3. Informasi ketinggian air } \\
\text { ditampilkan ke LCD }\end{array}$ \\
\hline Weakness & $\begin{array}{l}\text { 1. } \begin{array}{l}\text { Bergantung pada aliran arus } \\
\text { listrik. }\end{array} \\
\text { 2. Proses buka tutup pintu akan } \\
\text { terkendala jika ada sampah yang } \\
\text { menghalangi. }\end{array}$ \\
\hline Opportunities & $\begin{array}{l}\text { 1. Alat ini bekerja secara otomatis } \\
\text { Dapat dikembangkan menjadi } \\
\text { system peringatan dini waspada } \\
\text { banjir. }\end{array}$ \\
\hline Threats & $\begin{array}{l}\text { Komponen alat ini akan rusak } \\
\text { jika terendam air. } \\
\text { Sensor air yang digunakan tidak } \\
\text { akan aktif jika ada benda } \\
\text { penghalang. }\end{array}$ \\
\hline
\end{tabular}

Selanjutnya, penerapan strategi SWOT pada rancang bangun pintu air otomatis menggunakan water level float switch sensor berbasis mikrokontroler arduino uno dijelaskan pada tabel 2.

Tabel 2. Strategi Swot Rancang Bangun Pintu Air Otomatis

\begin{tabular}{|c|c|}
\hline Str & $\begin{array}{l}\text { 1. Perangkat ini dapat bekerja secara } \\
\text { otomatis dalam membuka dan } \\
\text { menutup pintu berdasarkan jumlah } \\
\text { sensor yang aktif pada dasar } \\
\text { bendungan. } \\
\text { 2. Pengembangan sistem menjadi } \\
\text { sistem peringatan dini waspada } \\
\text { banjir dapat berupa alarm maupun } \\
\text { pengiriman pesan singkat berupa } \\
\text { SMS kepada sejumlah masyarakat. }\end{array}$ \\
\hline $\begin{array}{c}\text { Strategi W- } \\
\text { O }\end{array}$ & $\begin{array}{l}\text { 1. Untuk mencegah terjadinya } \\
\text { pemadaman arus listrik saat terjadi } \\
\text { luapan air diperlukan batrai tower } \\
\text { BTS yang memiliki kapasitas besar } \\
\text { sebagai pengganti listrik. } \\
\text { 2. Pada posisi didepan daun pintu air } \\
\text { dibuat semacam jaring dari besi } \\
\text { atau kawat baja yang berfungsi } \\
\text { menyaring sampah agar tidak } \\
\text { langsung mengenai pintu yang } \\
\text { akan membuat kemacetan pada } \\
\text { proses buka tutup pintu. }\end{array}$ \\
\hline Stra & $\begin{array}{l}\text { 1. Pada perangkat utama, sensor } \\
\text { ultrasonik dan LCD dipasang } \\
\text { semacam case yang berguna untuk }\end{array}$ \\
\hline
\end{tabular}




\begin{tabular}{|c|l|}
\hline \multirow{1}{*}{ melindungi dari air hujan, ataupun } \\
benturan benda keras lainnya. \\
2. Pada sensor water level float \\
switch dipasang semacam case \\
yang dapat melindungi dari \\
sampah yang berada pada \\
bendungan. \\
\hline 1. Peletakan komponen utama \\
ditempatkan diposisi yang aman \\
dari jangkauan air, sensor yang \\
digunakan harus terlindungi. \\
Trategi W- & 2. Untuk mengatasi hal yang tidak \\
terduga dalam sistem otomatis \\
yang terpasang, pada pintu air juga \\
dilengkapi dengan sistem manual. \\
\hline
\end{tabular}

\section{B. Analisis}

Analisis sistem berjalan akan dijelaskan dengan menggunakan diagram use case yang ditampilkan pada gambar 1 dan diagram activity sistem berjalan pada gambar 2 .

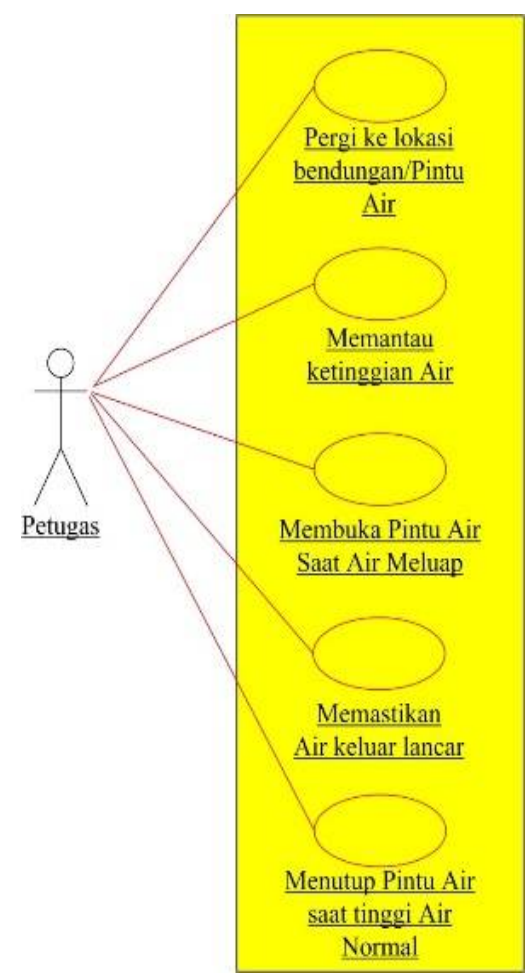

Gambar 1. Diagram Use Case Sistem Berjalan

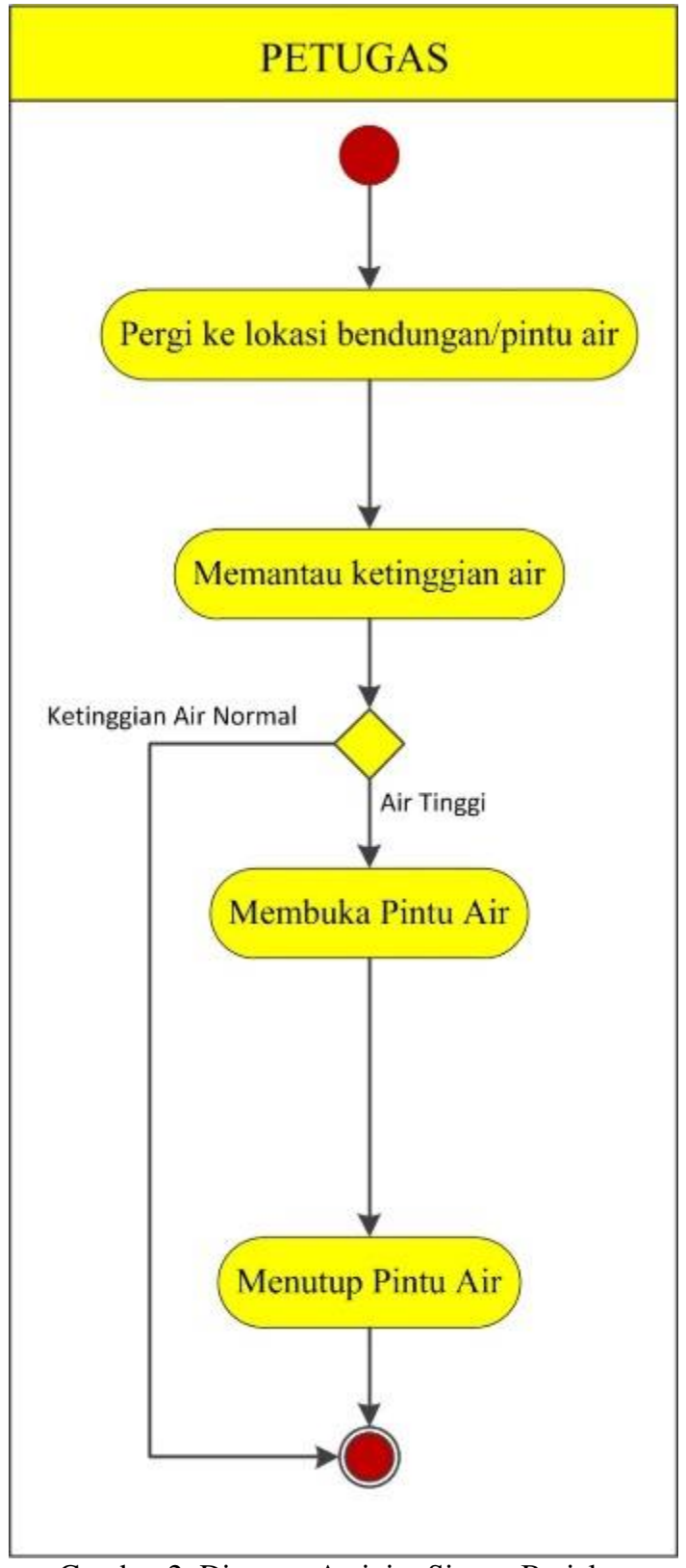

Gambar 2. Diagram Activity Sistem Berjalan

\section{Perancangan}

Cara kerja pintu otomatis ini adalah informasi ketinggian air akan ditampilkan pada LCD Display berdasarkan hasil pengukuran sensor utrasonic yang dipasang pada bagian atas pintu air. Di dalam bendungan telah dipasang dua buah sensor air jenis pelampung (water level float swtich) dimana sensor pertama diletakkan paling bawah, dan sensor kedua berada paling atas. Saat pintu air menyentuh sensor pertama (mengaktifkan sensor pertama), maka motor servo akan berputar sebesar 600 dan pada saat air menyentuh sensor air kedua (mengaktifkan sensor kedua), maka motor servo akan berputar sebesar 1100. Dan jika ketinggian air mulai 
berkurang dimana sensor kedua tidak aktif, maka motor servo akan berputar sebesar 600 dan jika ketinggian air kembali normal dimana sensor pertama tidak aktif maka motor servo akan bergerak menutup pintu air secara sempurna. Sensor air (water level float swicth) akan aktif jika posisi sensor tersebut terendam air.

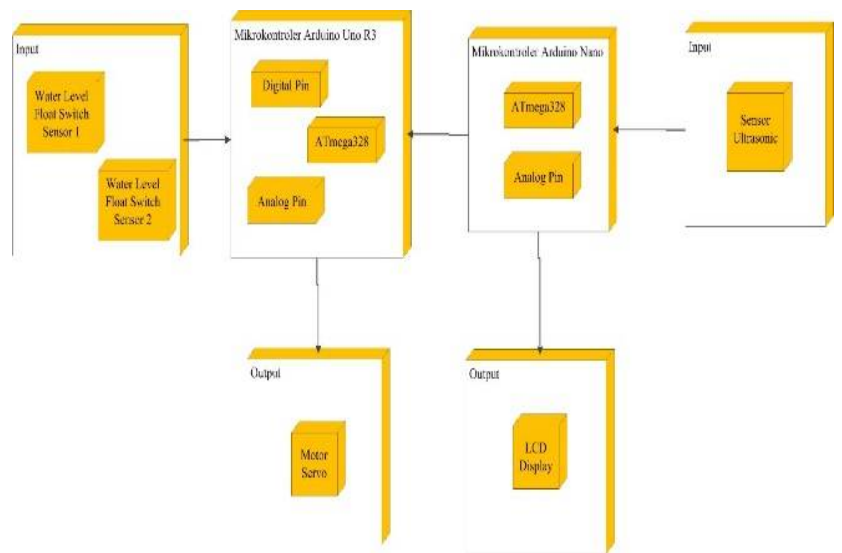

Gambar 3. Deployment Diagram Rancangan Pintu Air Otomatis

Dilihat dari deployment diagram pada gambar 3 dapat diketahui bahwa semua perangkat keras (hardware) saling berhubungan semua dalam perancangan pintu air otomatis ini. Pintu air terhubung langsung ke motor servo yang berfungsi membuka dan menutup pintu air.

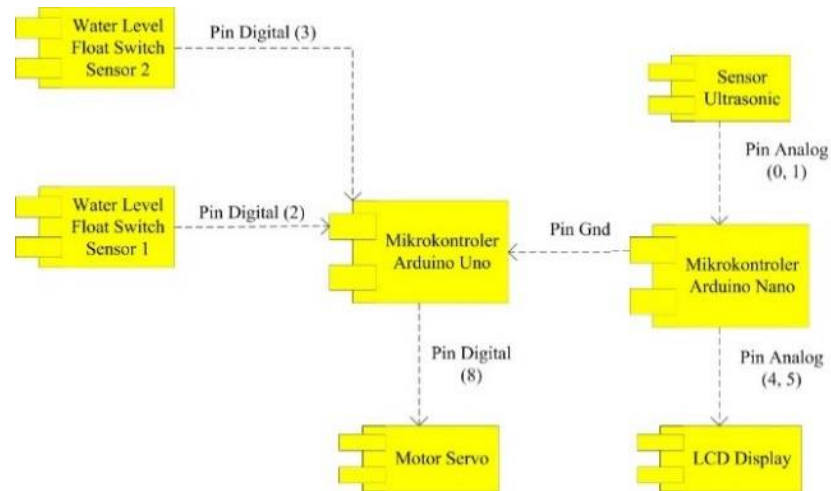

Gambar 4. Component Diagram Rancangan Pintu Air Otomatis

Dilihat dari diagram pada gambar 4, mikrokontroler arduino uno menerima masukan dari water level float switch sensor dan menghasilkan keluaran kemotor servo. Lalu mikrokontroler arduino nano menerima masukan dari sensor ultrasonik dan menghasilkan keluaran ke LCD Display.

Perancangan proses cara kerja water level float switch sensor disajikan dalam bentuk flowchart pada gambar 5 dan algoritma cara kerja water level float switch sensor dijelaskan pada gambar 6 .

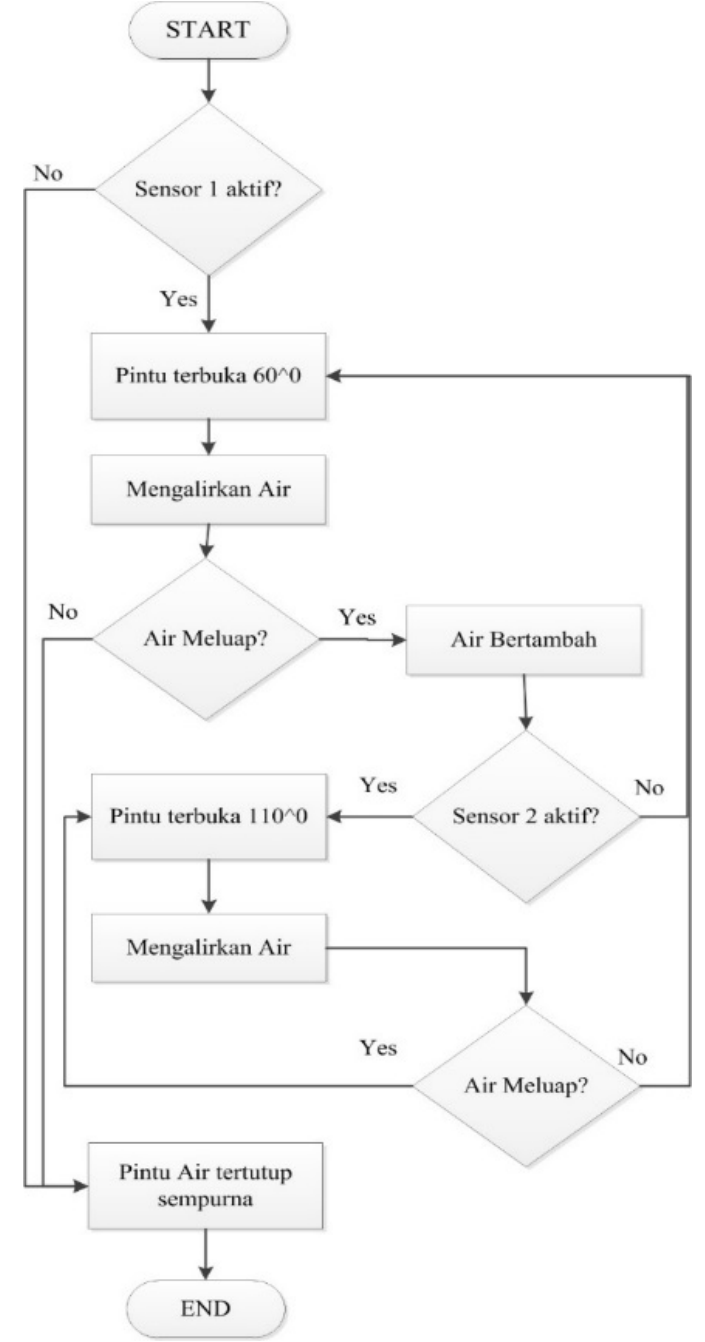

Gambar 5. Flowchart Cara Kerja Water Level Float Switch Sensor.

\begin{tabular}{|lc|}
\hline 1 & Start; \\
2 & Alat siap; \\
3 & if(Sensor 1 aktif?) \{ \\
4 & Pintu Terbuka $60^{0} ;$ \\
5 & Mengalirkan Air; \\
5 & if (Air Meluap?); \\
6 & Air bertambah; \\
7 & If(Sensor 2 aktif?) \{ \\
8 & Pintu terbuka $110^{0} ;$ \\
9 & Mengalirkan Air; \\
10 & While(!Air Meluap?) \{ \\
11 & Read Pintu Terbuka $\left.60^{0} ;\right\}$ \\
12 & Read Pintu terbuka $\left.110^{\circ} ;\right\}$ \\
13 & Read Pintu terbuka $\left.60^{\circ} ;\right\}$ \\
14 & Read Pintu Air tertutup sempurna; \\
15 & End; \\
\hline
\end{tabular}

Gambar 6. Algoritma Cara Kerja Water Level Float Switch Sensor. 
Perancangan cara kerja alat secara keseluruhan pada rancang bangun pintu air otomatis menggunakan water level float switch sensor berbasis mikrokontroler arduino uno disajikan dalam bentuk flowchart pada gambar 7 .

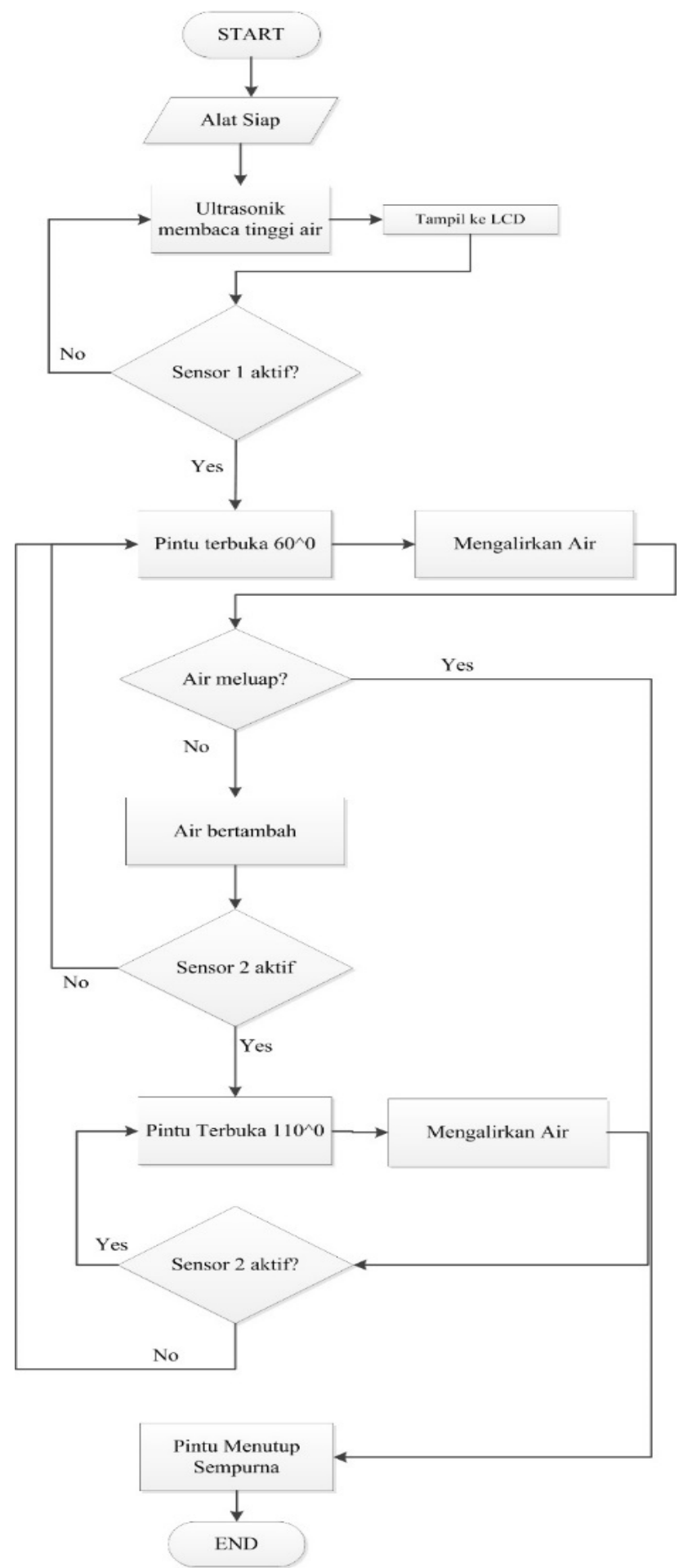

Gambar 7. Flowchart Output Rancang Bangun Pintu Air Otomatis
1 Start;

2 alat siap;

3 ultrasonik baca tinggi air;

4 Tampil ke LCD;

5 if (Sensor 1 aktif?)

6 \{ Pintu terbuka $60^{\circ}$;

7 mengalirkan air;

8 if (!air meluap?)

9 \{ Air bertambah;

10 if(sensor 2 aktif?)

11 Pintu terbuka $110^{0}$;

12 mengalirkan air;

13 if (sensor 2 aktif?)

14 Read Pintu terbuka $\left.110^{\circ}\right\}$ \}

15 Read Pintu terbuka $\left.60^{\circ} ;\right\}$

16 Pintu menutup sempurna; $\}$

17 Read ultrasonik baca tinggi air;

18 End;

Gambar 3.8 Algoritma Output Rancang Bangun Pintu Air Otomatis

\section{Implementasi}

Implementasi dari rancang bangun pintu air otomatis menggunakan water level float switch sensor berbasis mikrokontroler arduino uno terdiri dari instalasi perangkat keras, instalasi perangkat lunak Arduino IDE versi yang digunakan dalam rancangan ini adalah 1.0, pemrograman atau coding serta pengujian yang menggunakan metode BlackBox Testing.

1) Instalasi Perangkat Keras

Instalasi rangkaian perangkat keras pada gambar 3.9 dan gambar 3.10 adalah rangkaian alat secara keseluruhan yang terpasang pada prototype.

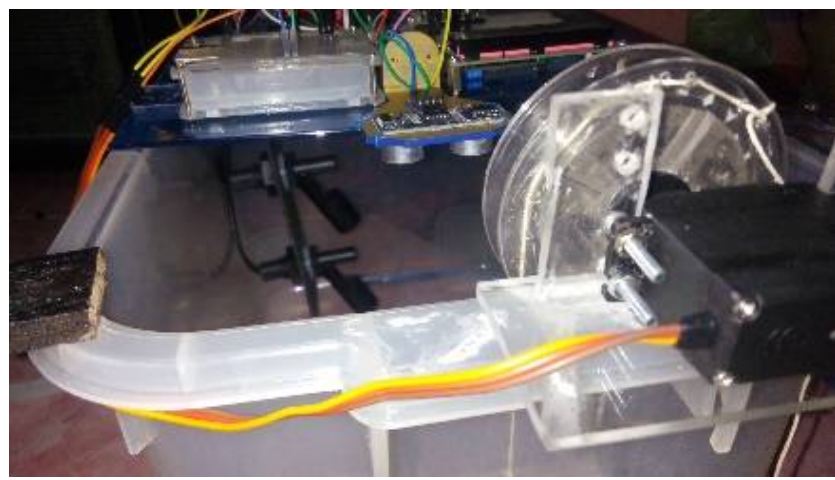

Gambar 9. Rancangan Pintu Air Otomatis Tampak Dalam 


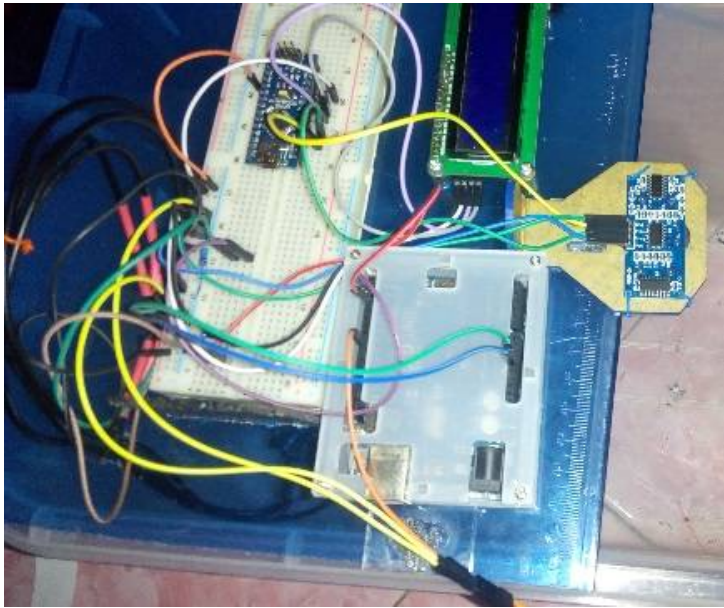

Gambar 1.0 Rancangan Alat

Dari gambar 3.9 dan 3.10 rancangan pintu air otomatis menggunakan dua buah water level float switch sensor, satu sensor ultrasonik, satu LCD display, satu motor servo, satu mikrokontroler arduino uno dan nano.

\section{2) Blackbox Testing}

Tahapan pengujian adalah tahapan akhir saat semua proses dilalui dengan tujuan untuk mengetahui apakah alat yang dirancang telah sesuai dengan hasil yang diharapkan.

Pengujian ini menggunakan metode BlackBox Testing, dimana pengujian ini memfokuskan pada kebutuhan fungsional perangkat dengan tujuan berusaha menemukan kesalahan, kesalahan yang dimaksud adalah kesalahan fungsi, kesalahan intreface, kesalahan struktur data, ataupun kesalahan kinerja.

Tabel 3. Blackbock testing

\begin{tabular}{|l|l|l|c|}
\hline No & \multicolumn{1}{|c|}{ Prosedur } & \multicolumn{1}{|c|}{$\begin{array}{c}\text { Hasil yang } \\
\text { diharapkan }\end{array}$} & Validasi \\
\hline 1 & $\begin{array}{l}\text { Air dimasukan } \\
\text { kedalam wadah } \\
\text { secara bertahap } \\
\text { hingga water level } \\
\text { wloat switch } \\
\text { sensor pertama } \\
\text { aktif }\end{array}$ & $\begin{array}{l}\text { Pintu air terbuka } \\
\text { secara otomatis } \\
\text { dengan putaran } \\
\text { servo 60 }\end{array}$ & Valid \\
\hline 2 & $\begin{array}{l}\text { Mengurangi air } \\
\text { sampai water } \\
\text { level wloat switch } \\
\text { sensor pertama } \\
\text { tidak aktif }\end{array}$ & $\begin{array}{l}\text { Pintu air menutup } \\
\text { otomatis sempurna }\end{array}$ & Valid \\
\hline 3 & $\begin{array}{l}\text { Air dimasukan } \\
\text { kedalam wadah } \\
\text { sampai water } \\
\text { level float switch } \\
\text { sensor kedua aktif }\end{array}$ & $\begin{array}{l}\text { Pintu air terbuka } \\
\text { secara otomatis } \\
\text { dengan putaran } \\
\text { servo 110 }\end{array}$ & Valid \\
\hline 4 & $\begin{array}{l}\text { Air dimasukan } \\
\text { kedalam wadah } \\
\text { secara bertahap }\end{array}$ & $\begin{array}{l}\text { Sensor ultrasonik } \\
\text { dapat mengukur } \\
\text { ketinggian air dan } \\
\text { menampilkannya ke } \\
\text { LCD display }\end{array}$ & Valid \\
\hline
\end{tabular}

\section{PEnUtup}

\section{A. Kesimpulan}

Berdasarkan hasil pembahasan dan pengujian yang telah dilakukan pada rancang bangun pintu air otomatis menggunakan water level flow switch sensor dan sensor ultrasonic berbasis mikrokontroler arduino uno, maka dapat diambil kesimpulan sebagai berikut:

- Meringankan tugas manusia dalam mengontrol ketinggian air dibendungan, serta dapat mengurangi kelalaian manusia dalam bertugas.

- Dengan adanya sistem pintu air otomatis ini diharapkan mampu mengontrol ketinggian atau volume air pada suatu bendungan dengan lebih efektif.

- Kekurangan dari alat yang dirancang ini adalah proses buka dan tutup pintu air tidak berjalan secara maksimal apabila sekitar pintu terdapat sampah atau benda-benda yang menghalangi.

\section{B. Saran}

Penelitian yang dilakukan ini tentunya tidak terlepas dari pada kekurangan dan kelemahan. Oleh karena itu, untuk pengembangan sistem lebih lanjut, perlu diperhatikan beberapa hal berikut ini:

- Pintu air masih merembes, penutupan pintu masih belum sempurna. Diperlukan alat tambahan agar air tidak merembes.

- Dalam protoype ini menggunakan hardware atau perangkat keras dengan spesifikasi minimum, untuk pengembangan selanjutnya dapat menggunakan hardware dengan spesifikasi yang lebih baik.

- Sistem ini dapat dikembangkan kembali untuk sistem peringatan dini waspada banjir.

\section{DAFTAR PUSTAKA}

[1] Adi Nugroho. 2010. Rekayasa Perangkat Lunak Berbasis Objek dengan Metode USDP. Andi. Yogyakarta.

[2] Albir, Sinan Si. 2003. Learning UML. O’Reilly \& Associates, Inc., 1005 Gravenstein Highway North, Sebastopol, CA 95472.

[3] Andrianto, Heri dan Aan Darmawan. 2016. Arduino Belajar Cepat dan Pemrograman. Informatika. Bandung.

[4] Booch, Grady. 2005. Object Oriented Analysis and Design with Application 2nd Edition. United States of America.R. Nicole, "Title of paper with only first word capitalized," J. Name Stand. Abbrev., in press.

[5] Fowler, Martin.2005. UML Distilled. Edisi 3. Andi. Yogyakarta.

[6] Gries, David, Fred B. Schneider. 2005. An Integrated Approach to Software Engineering Third Edition. Pankaj Jalote. Indian Institute of Technology Kampur India.

[7] Herlawati, dan Widodo. 2011. Menggunakan UML. Informatika Bandung.

[8] Krismiaji. 2010. Sistem Informasi Akuntasi. UPP AMP YKPN. Yogyakarta.

[9] Munawar. 2005. Pemodelan Visual Menggunakan UML. Graha Ilmu. Yogyakarta 